\title{
Evaluation of various equations for estimating renal function in elderly Chinese patients with type 2 diabetes mellitus
}

This article was published in the following Dove Press journal:

Clinical Interventions in Aging

9 October 2017

Number of times this article has been viewed

\author{
Mei Guo' \\ Jian-Ying $\mathrm{Niu}^{2}$ \\ Xian-Wu $\mathrm{Ye}^{2}$ \\ Xiao-Jie $\mathrm{Han}^{2}$ \\ Ying Zha ${ }^{2}$ \\ Yang Hong ${ }^{2}$ \\ Hong Fang ${ }^{3}$ \\ Yong $\mathrm{Gu}^{2,4}$
}

'Zhongshan-Xuhui Hospital, Affiliated with Fudan University, ${ }^{2}$ The Fifth People's Hospital of Shanghai, Fudan University, ${ }^{3}$ Shanghai Minhang Center for Disease Control and Prevention, ${ }^{4}$ Department of Nephrology, Huashan Hospital, Fudan University, Shanghai, China
Correspondence: Yong Gu Department of Nephrology, the Fifth People's Hospital of Shanghai, Fudan University, No 80I Heqing Road, Minhang District, Shanghai, China Tel +86 2I 5235 946I Email yonggu@vip.l63.com
Background: The clinical assessment of kidney function based on the estimated glomerular filtration rate (GFR) in older patients remains controversial. This study evaluated the concordance and feasibility of using various creatinine-based equations for estimating GFR in elderly Chinese patients with type 2 diabetes mellitus (T2DM).

Methods: A cross-sectional analytical study was conducted in 21,723 older diabetic patients ( $\geq 60$ years) based on electronic health records (EHR) for Minhang District, Shanghai, China. The concordance of chronic kidney disease (CKD) classification among different creatininebased equations was assessed based on Kappa values, intraclass correlation coefficient (ICC) statistics, and the eGFR agreement between the equations was tested using Bland-Altman plots. The GFR was estimated using the Cockcroft-Gault (CG), Berlin Initiative Study 1 (BIS1), simplified Modification of Diet in Renal Disease (MDRD), MDRD modified for Chinese populations (mMDRD), chronic kidney disease epidemiology collaboration (CKD-EPI), CKD-EPI in Asians (CKD-EPI-Asia), and Ruijin equations.

Results: Overall, the proportion of CKD stages 3-5 (eGFR $\left.<60 \mathrm{~mL} / \mathrm{min} / 1.73 \mathrm{~m}^{2}\right)$ was calculated as $28.9 \%, 39.1 \%, 11.8 \%, 8.4 \%, 14.3 \%, 11.5 \%$, and $12.7 \%$ by the eGFR ${ }_{\mathrm{CG}}$, eGFR ${ }_{\mathrm{BIS} 1}$,

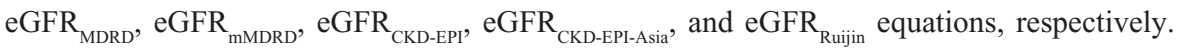
The concordance of albuminuria and decreased eGFR based on the different equations was poor by both the Kappa $(<0.2)$ and ICC $(<0.4)$ statistics. The CKD-EPI-Asia equation resulted in excellent concordance with the CKD-EPI (ICC $=0.931$ ), MDRD (ICC $=0.963$ ), mMDRD ( ICC $=0.892$ ), and Ruijin ( $\mathrm{ICC}=0.956$ ) equations for the classification of CKD stages, whereas the BIS1 equation exhibited good concordance with the $\mathrm{CG}$ equation ( $\mathrm{ICC}=0.809$ ). In addition, significant differences were observed for CKD stage 1 among all these equations.

Conclusion: Accurate GFR values are difficult to estimate using creatinine-based equations in older diabetic patients. Kidney function is complex, and the staff need to be aware of the individualized consideration of other risk factors or markers of reduced renal function in clinical practice.

Keywords: estimated glomerular filtration rate, renal function, elderly, type 2 diabetes mellitus, electronic health records

\section{Introduction}

The number of older patients with chronic kidney disease (CKD) and/or end-stage renal disease (ESRD) has increased dramatically in China during the past two decades. ${ }^{1}$ $\mathrm{CKD}$ is associated with various comorbid conditions in older people, such as cardiovascular disease and disability, which in turn increase the risk of hospitalization and death. Diabetes mellitus has become one of the main causes of CKD in older patients 
in China. ${ }^{2}$ The early identification and appropriate management of CKD in diabetic patients are important measures to slow its progression, for appropriately correcting the dosage of renally eliminated medications, and for avoiding potential drug toxicity. The direct measurement of glomerular filtration rate (GFR) using a substance exclusively filtered by the kidneys, such as inulin or other markers (eg, Tc-99mdiethylene triamine pentaacetic acid, 51Cr-labeled ethylene diamine tetraacetic acid, and ${ }^{125} \mathrm{I}$-iothalamate), is the most reliable method to assess renal function. ${ }^{3}$ However, these exogenous markers need to be infused or injected using costly and labor-intensive procedures to measure GFR. These evaluations are impractical in large numbers of older subjects. In clinical practice, serum creatinine (Scr)-based equations for calculating estimated glomerular filtration rate (eGFR) are important tools for identifying geriatric patients with CKD and for allocating appropriate drug dosage in these patients. The most often employed and analyzed equations include the Cockcroft-Gault (CG), ${ }^{4}$ Modification of Diet in Renal Disease (MDRD), ${ }^{5,6}$ MDRD modified for Chinese populations (mMDRD), ${ }^{7}$ and chronic kidney disease epidemiology collaboration (CKD-EPI) equations. ${ }^{8}$ These equations use information on age, gender, Scr, and race. Weight is also a factor in the $\mathrm{CG}$ equation. However, the clinical assessment of kidney function based on eGFR in older patients remains controversial. Older individuals experience age-related loss of muscle mass, and sarcopenia has been reported in 1\%-29\% of community-dwelling populations, ${ }^{9}$ which may influence body weight and Scr levels. Malnourished patients are particularly at risk of having decreased eGFR, even when they have normal Scr levels. ${ }^{10}$ Race is also an important determinant of GFR estimation due to differences in dietary habits and body composition. ${ }^{11}$ All of these factors can influence the accuracy of the results obtained when applying Scr-based equations. A multiple-race and -ethnicity study suggested that the use of a four-level race CKD-EPI equation (Black, Asian, Native American and Hispanic, White and other) in Asians (CKD-EPI-Asia) may improve the accuracy of results obtained for Asians. ${ }^{12}$

Currently, the American Diabetes Association recommends an annual screening for diabetic kidney disease based on an evaluation of the urinary excretion of albumin and GFR, as estimated using equations including Scr, such as the MDRD or the CKD-EPI equation. ${ }^{13}$ However, some studies suggest that evaluating eGFR based on the CKD-EPI equation provides improved risk prediction for heart failure, ESRD and cardiovascular mortality compared with the value of eGFR obtained using the MDRD equation. ${ }^{14-16}$ It has also been reported that the MDRD equation significantly underestimates GFR in diabetic patients with microalbuminuria or overt diabetic nephropathy. ${ }^{17}$ One study, which was conducted in Type 2 diabetic patients in a Korean population, suggested that the value of eGFR obtained using the CKD-EPI equation can more accurately stratify earlier-stage CKD among type 2 diabetic patients with nephropathy than the value of eGFR obtained using the MDRD equation. ${ }^{18}$ While some studies have suggested that the performances of CKD-EPI and MDRD are comparable, ${ }^{19}$ others have suggested that the CKD-EPI formula does not exhibit better performance than the simplified MDRD formula for estimating GFR in diabetic patients. ${ }^{20}$ Using ${ }^{99 \mathrm{~m}} \mathrm{Tc}-\mathrm{DTPA}$ dynamic renal imaging as the gold standard, some studies in China have suggested that the Ruijin formula is more accurate than MDRD for estimating GFR in Chinese diabetes patients (the rate of achieving 30\% accuracy was over $70.0 \%$ ), ${ }^{21,22}$ and one study suggested that this method is suitable for older diabetic patients (mean age of $70.3 \pm 6.4$ years $).{ }^{21}$ Furthermore, some studies have suggested that the Ruijin formula is more suitable for estimating GFR during the early stage of CKD in Chinese diabetes patients than the CKD-EPI equation. ${ }^{23,24}$ However, the sample size in each of the previous Chinese studies was not larger than 300 diabetic patients. The Ruijin formula was refitted based on the MDRD by investigating 760 Chinese cases of CKD hospitalized at the Shanghai Jiaotong University-affiliated Ruijin Hospital during 2002-2005. ${ }^{25}$ The feasibility of using this formula needs verification in a large sample of diabetic patients. Some recent studies have suggested that the use of the Berlin Initiative Study 1 (BIS1) equation based on Scr is more suitable and accurate for estimating GFR in older patients, including diabetic patients; this equation was developed and validated in a population of older adults aged 70 years or more. ${ }^{26}$ Studies comparing the MDRD, CKD-EPI, BIS1, CKD-EPI-Asia, and Ruijin equations are rare. The present study aimed to evaluate the concordance of estimating renal function using the $\mathrm{CG}, \mathrm{MDRD}, \mathrm{mMDRD}$, CKD-EPI, BIS1, CKD-EPI-Asia, and Ruijin equations for older patients with type 2 diabetes mellitus (T2DM) based on electronic health record (EHR) data for the Minhang District of Shanghai.

\section{Methods \\ Subjects}

For this study, data collected between October 1, 2012 and September 30, 2013 were extracted from the EHR for all 55,533 patients participating in a diabetes management program in the Minhang district of Shanghai, China, including 
13 community care centers. In total, 25,021 elderly patients diagnosed with T2DM (International Classification of Diseases [ICD]-10 codes E10-E14) were eligible for analysis after excluding patients for whom incomplete data were available regarding Scr, urinary albumin to creatinine ratio (ACR), and standard hemoglobin A1c (HbA1c; n=24,491) or who were under the age of 60 years $(n=6,021)$. Details of the data extraction have been described previously. ${ }^{27}$ After data cleaning and excluding patients with seriously abnormal Scr $(<53 \mu \mathrm{mol} / \mathrm{L}$ or $>618 \mu \mathrm{mol} / \mathrm{L})$ levels, a total of 21,723 cases of older diabetic patients remained. Diabetic history and data from physical examinations, including measurements of blood pressure, body height, weight, waist circumference, fasting blood glucose, HbA1c (measured using standard high-performance liquid chromatography), Scr measured by Jaffe's kinetic method, and the urinary albumin-to-creatinine ratio (ACR, milligram per gram), were extracted. The study adhered to the Declaration of Helsinki and was approved by the ethics committee of the Fifth Hospital of Shanghai, Fudan University, Shanghai, China (EC 2010-024). A consent form was not required because this study was based on the secondary data analysis of a pre-existing, de-identified dataset.

\section{Measurements}

GFR was estimated using the CG, MDRD, mMDRD, CKDEPI, CKD-EPI-Asia, Ruijin and BIS1 equations, which are presented below:

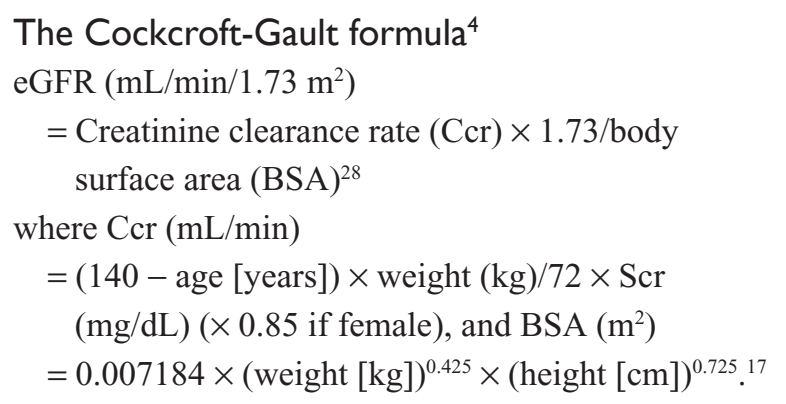

\section{MDRD study equation ${ }^{6}$}

eGFR $\left(\mathrm{mL} / \mathrm{min} / 1.73 \mathrm{~m}^{2}\right)$

$$
=186.3 \times \mathrm{Scr}^{-1.154} \times\left(\text { age }[\text { years] })^{-0.203}\right.
$$$$
\times[0.742 \text { for women }]) \times(1.210 \text { if black }) \text {, where }
$$

$\mathrm{Scr}$ is measured in $\mathrm{mg} / \mathrm{dL}(1 \mathrm{mg} / \mathrm{dL}=88.4 \mu \mathrm{mol} / \mathrm{L})$

\section{mMDRD equation ${ }^{7}$}

eGFR $\left(\mathrm{mL} / \mathrm{min} / 1.73 \mathrm{~m}^{2}\right)$

$$
=175 \times \mathrm{Scr}^{-1.234} \times \mathrm{age}^{-0.179} \times 0.79(\text { if female })
$$

\section{CKD-EPI equation ${ }^{8}$}

Female $(\mathrm{Scr} \leq 0.7)$, eGFR $\left(\mathrm{mL} / \mathrm{min} / 1.73 \mathrm{~m}^{2}\right)$

$=144 \times(\mathrm{Scr} / 0.7)^{-0.329} \times(0.993)^{\mathrm{Age}}(\times 1.159$ if black $)$

$(\mathrm{Scr}>0.7)$, eGFR $\left(\mathrm{mL} / \mathrm{min} / 1.73 \mathrm{~m}^{2}\right)$

$=144 \times(\mathrm{Scr} / 0.7)^{-1.209} \times(0.993)^{\mathrm{Age}}(\times 1.159$ if black $)$

Male $(\mathrm{Scr} \leq 0.9)$, eGFR $\left(\mathrm{mL} / \mathrm{min} / 1.73 \mathrm{~m}^{2}\right)$

$=141 \times(\mathrm{Scr} / 0.9)^{-0.411} \times(0.993)^{\text {Age }}(\times 1.159$ if black $)$

$(\mathrm{Scr}>0.9)$, eGFR $\left(\mathrm{mL} / \mathrm{min} / 1.73 \mathrm{~m}^{2}\right)$

$=141 \times(\mathrm{Scr} / 0.9)^{-1.209} \times(0.993)^{\mathrm{Age}}(\times 1.159$ if black $)$

\section{CKD-EPI-Asia equation ${ }^{12}$}

Female $(\mathrm{Scr} \leq 0.7)$ eGFR $\left(\mathrm{mL} / \mathrm{min} / 1.73 \mathrm{~m}^{2}\right)$

$=151 \times(\mathrm{Scr} / 0.7)^{-0.328} \times(0.993)^{\mathrm{Age}}$

$(\mathrm{Scr}>0.7)$, eGFR $\left(\mathrm{mL} / \mathrm{min} / 1.73 \mathrm{~m}^{2}\right)$

$=151 \times(\mathrm{Scr} / 0.7)^{-1.210} \times(0.993)^{\mathrm{Age}}$

Male $(\mathrm{Scr} \leq 0.9)$, eGFR $\left(\mathrm{mL} / \mathrm{min} / 1.73 \mathrm{~m}^{2}\right)$

$=149 \times(\mathrm{Scr} / 0.9)^{-0.415} \times(0.993)^{\mathrm{Age}}$

$(\mathrm{Scr}>0.9)$, eGFR $\left(\mathrm{mL} / \mathrm{min} / 1.73 \mathrm{~m}^{2}\right)$

$=149 \times(\mathrm{Scr} / 0.9)^{-1.210} \times(0.993)^{\mathrm{Age}}$

\author{
Ruijin equation ${ }^{25}$ \\ eGFR $\left(\mathrm{mL} / \mathrm{min} / 1.73 \mathrm{~m}^{2}\right)$ \\ $=234.96 \times(\mathrm{Scr})^{-0.926} \times(\text { Age })^{-0.280} \times 0.828($ if female $)$ \\ BISI equation ${ }^{26}$ \\ eGFR $\left(\mathrm{mL} / \mathrm{min} / 1.73 \mathrm{~m}^{2}\right)$ \\ $=3,736 \times(\text { Scr })^{-0.87} \times(\text { Age })^{-0.95} \times 0.82($ if female $)$
}

CKD was defined as either reduced renal function (low eGFR) and/or kidney damage. Kidney damage was estimated as albuminuria $>30 \mathrm{mg} / \mathrm{g}$ creatinine. ${ }^{29}$ Albuminuria categories were based on ACR in a spot urine sample: $\mathrm{A} 1,<30 \mathrm{mg} / \mathrm{g}$ (normal to mildly increased); A2, 30 to $<300 \mathrm{mg} / \mathrm{g}$ (moderately increased); and $\mathrm{A} 3,>300 \mathrm{mg} / \mathrm{g}$ (severely increased). The stages of CKD were as follows: Stage 1, albuminuria with an eGFR of $\geq 90 \mathrm{~mL} / \mathrm{min} / 1.73 \mathrm{~m}^{2}$; stage 2, albuminuria with an eGFR of $60-89 \mathrm{~mL} / \mathrm{min} / 1.73 \mathrm{~m}^{2}$; stage $3 \mathrm{a}$, an eGFR of $45-59 \mathrm{~mL} / \mathrm{min} / 1.73 \mathrm{~m}^{2}$; stage $3 \mathrm{~b}$, an eGFR of $30-44 \mathrm{~mL} /$ $\mathrm{min} / 1.73 \mathrm{~m}^{2}$; stage 4 , an eGFR of $15-29 \mathrm{~mL} / \mathrm{min} / 1.73 \mathrm{~m}^{2}$; stage 5 , an eGFR of $<15 \mathrm{~mL} / \mathrm{min} / 1.73 \mathrm{~m}^{2}$ or dialysis. ${ }^{30}$ Stages with eGFR values of $<60 \mathrm{~mL} / \mathrm{min} / 1.73 \mathrm{~m}^{2}$ (stages $3-5$ ) were considered to indicate reduced renal function.

\section{Statistical analysis}

For data processing, the Statistical Product and Service Solutions-IBM SPSS Statistics 19.0 (Armonk, NY, USA) and GraphPad Prism 5 (La Jolla, CA, USA) were used. Qualitative 
variables are presented as frequencies and percentages, and quantitative variables are presented as the means and standard deviations (mean $\pm \mathrm{SD}$ ). BMI was evaluated in the following 2 ways: 1 ) as 4 categories (underweight $<18.5$, normal weight 18.5-23.9, overweight 24-27.9, and obese $\left.\geq 28\left[\mathrm{~kg} / \mathrm{m}^{2}\right]\right)^{31}$ and 2) as a continuous variable. Abdominal obesity was defined as waist circumference $\geq 90 \mathrm{~cm}$ for men and $\geq 80 \mathrm{~cm}$ for women. ${ }^{32}$ Concordance between the different eGFR estimations was analyzed by calculating intraclass correlation coefficients (ICCs, two-way mixed model) together with the respective $95 \%$ confidence interval and Kappa statistic. Kappa values of 0.0-0.2 indicate slight agreement, values of $0.21-0.40$ indicate fair agreement, values of $0.41-0.60$ indicate moderate agreement, values of 0.61-0.80 indicate substantial agreement, and values of $0.81-1.0$ indicate almost perfect or perfect agreement. ${ }^{33,34}$ Higher ICC values indicate greater inter-rater agreement, with ICC values of $<0.4$ indicating poor agreement, values of $0.40-0.59$ indicating fair agreement, values of $0.60-0.74$ indicating good agreement, and values of $0.75-1.0$ indicating excellent agreement. ${ }^{34}$ Bland-Altman plots were used to assess the pairwise agreement between eGFR levels obtained using different equations. ${ }^{35}$ Two-sided $P<0.05$ was considered to indicate statistical significance.

\section{Results}

\section{Subject characteristics by age group}

Table 1 summarizes the demographic and some clinical characteristics of the 21,723 diabetic patients. The mean age of all patients was $70.70 \pm 7.35$ (range $60-95$ years). Almost $55 \%$ of the patients were $60-69$ years old $(11,835,54.5 \%)$, and 2,515 (11.6\%) were $\geq 80$ years old. More females $(11,146,51.3 \%)$ than males $(10,577,48.7 \%)$ were included, especially in the $\geq 80$-year-old age group (females: $1,502,59.7 \%$; males: $1,013,40.3 \%)$. The proportion of obese (BMI $\geq 28 \mathrm{~kg} / \mathrm{m}^{2}$ ) and abdominally obese patients decreased with age, while the proportion of underweight (BMI $<18.5 \mathrm{~kg} / \mathrm{m}^{2}$ ) patients increased from $1.2 \%$ in the $60-69$ years age group to $4 \%$ in the $\geq 80$ years age group.

Mean eGFR differed according to the formula used and decreased with aging. The lowest levels were observed for GFR values that were estimated using the BIS1 equation (70.11 \pm 15.48$)$, similar values were obtained using the CG equation (70.20 \pm 18.18 ), and the highest value for eGFR

Table I Demographic and clinical characteristics of study population by age groups

\begin{tabular}{|c|c|c|c|c|c|}
\hline Characteristics & Total & $60-69$ years & 70-79 years & $\geq 80$ years & $P$-value \\
\hline Number & 21,723 & II,835 (54.5\%) & 7,373 (33.9\%) & $2,515(11.6 \%)$ & - \\
\hline Age (years) & $70.70 \pm 7.35$ & $64.99 \pm 2.98$ & $75.34 \pm 2.90$ & $83.95 \pm 2.86$ & $<0.001$ \\
\hline Female & II,I 46 (5I.3\%) & $5,803(49.0 \%)$ & $3,841(52.1 \%)$ & I,502 (59.7\%) & $<0.001$ \\
\hline Duration of T2DM (years) & $8.95 \pm 6.25$ & $8.05 \pm 5.52$ & $9.84 \pm 6.73$ & $10.60 \pm 7.25$ & $<0.001$ \\
\hline Fasting glucose $(\mathrm{mmol} / \mathrm{L})$ & $8.11 \pm 2.80$ & $8.17 \pm 2.77$ & $8.1 I \pm 2.8 I$ & $7.85 \pm 2.89$ & $<0.001$ \\
\hline Waist circumference $(\mathrm{cm})$ & $84.82 \pm 7.79$ & $85.07 \pm 7.74$ & $84.60 \pm 7.70$ & $84.36 \pm 8.22$ & $<0.001$ \\
\hline Abdominal obesity & II,353 (52.3\%) & 6,175 (54.4\%) & $3,784(33.3 \%)$ & I,394 (I2.3\%) & 0.002 \\
\hline BMI $\left(\mathrm{kg} / \mathrm{m}^{2}\right)$ & $24.20 \pm 2.98$ & $24.45 \pm 2.97$ & $23.99 \pm 2.95$ & $23.66 \pm 3.02$ & $<0.001$ \\
\hline$<18.5$ & 409 (1.9\%) & $139(1.2 \%)$ & $170(2.3 \%)$ & $100(4.0 \%)$ & $<0.001$ \\
\hline $18.5-23.9$ & 10,435 (48.0\%) & $5,389(45.5 \%)$ & 3,725 (50.5\%) & I,32। (52.5\%) & - \\
\hline $24-27.9$ & $8,664(39.9 \%)$ & 4,958 (4I.9\%) & $2,813(38.2 \%)$ & $893(35.5 \%)$ & - \\
\hline$\geq 28$ & $2,215(10.2 \%)$ & I,349 (I I.4\%) & $665(9.0 \%)$ & $201(8.0 \%)$ & - \\
\hline Serum creatinine $(\mathrm{mmol} / \mathrm{L})$ & $77.98 \pm 25.55$ & $75.08 \pm 22.99$ & $80.07 \pm 26.65$ & $85.48 \pm 31.04$ & $<0.001$ \\
\hline HbAlc (\%) & $7.29 \pm 1.72$ & $7.30 \pm 1.69$ & $7.30 \pm 1.74$ & $7.22 \pm 1.76$ & 0.077 \\
\hline $\mathrm{HbAlc}(\%, \leq 7.0 \%)$ & II,663 (53.7\%) & $6,312(53.3 \%)$ & 3,931 (53.3\%) & $\mathrm{I}, 420(56.5 \%)$ & 0.012 \\
\hline Hypertension (yes) & $13,1 \mid 2(60.4 \%)$ & $6,36 \mathrm{I}(53.7 \%)$ & $4,953(67.2 \%)$ & I,798 (7I.5\%) & $<0.001$ \\
\hline Albuminuria $(A C R \geq 30 \mathrm{mg} / \mathrm{g}$ ) & 7,637 (35.2\%) & $3,742(31.6 \%)$ & $2,874(39.0 \%)$ & $\mathrm{I}, 02 \mathrm{I}(40.6 \%)$ & $<0.001$ \\
\hline $\mathrm{eGFR}_{\mathrm{CG}}\left(\mathrm{mL} / \mathrm{min} / 1.73 \mathrm{~m}^{2}\right)$ & $70.20 \pm 18.18$ & $78.67 \pm 16.05$ & $63.18 \pm 14.45$ & $50.92 \pm 13.26$ & $<0.001$ \\
\hline $\mathrm{eGFR}_{\mathrm{BISI}}\left(\mathrm{mL} / \mathrm{min} / \mathrm{l} .73 \mathrm{~m}^{2}\right)$ & $70.11 \pm 15.48$ & $77.35 \pm 13.53$ & $63.87 \pm 12.49$ & $54.35 \pm 11.93$ & $<0.001$ \\
\hline $\mathrm{eGFR}_{\mathrm{mMDRD}}\left(\mathrm{mL} / \mathrm{min} / \mathrm{l} .73 \mathrm{~m}^{2}\right)$ & $91.61 \pm 23.04$ & $96.50 \pm 21.88$ & $87.78 \pm 22.54$ & $79.82 \pm 23.38$ & $<0.001$ \\
\hline $\mathrm{eGFR}_{\text {MDRD }}\left(\mathrm{mL} / \mathrm{min} / \mathrm{l} .73 \mathrm{~m}^{2}\right)$ & $83.86 \pm 20.73$ & $88.46 \pm 19.79$ & $80.29 \pm 20.09$ & $72.69 \pm 20.63$ & $<0.001$ \\
\hline eGFR $_{\text {CKD-EPI }}\left(\mathrm{mL} / \mathrm{min} / \mathrm{I} .73 \mathrm{~m}^{2}\right)$ & $78.23 \pm 16.41$ & $83.79 \pm 14.40$ & $73.81 \pm 15.49$ & $64.97 \pm 16.38$ & $<0.001$ \\
\hline eGFR ${ }_{\text {CKD-EPI-Asia }}\left(\mathrm{mL} / \mathrm{min} / \mathrm{I} .73 \mathrm{~m}^{2}\right)$ & $82.36 \pm 17.35$ & $88.23 \pm 15.25$ & $77.70 \pm 16.37$ & $68.35 \pm 17.29$ & $<0.001$ \\
\hline $\mathrm{eGFR}_{\text {Ruiji }}\left(\mathrm{mL} / \mathrm{min} / \mathrm{l} .73 \mathrm{~m}^{2}\right)$ & $76.91 \pm 15.29$ & $80.97 \pm 14.25$ & $73.67 \pm 14.68$ & $67.32 \pm 15.28$ & $<0.001$ \\
\hline
\end{tabular}

Notes: Data are means \pm SD or $\mathrm{n}(\%)$. All percentages are column percentage.

Abbreviations: ACR, albumin to creatinine ratio; BISI, Berlin Initiative Study I equation; BMI, body mass index; CG, Cockcroft-Gault equation; CKD-EPI, chronic kidney disease epidemiology collaboration; CKD-EPI-Asia, CKD-EPI equation in Asians; Chinese-Ruijin, Ruijin equation; eGFR, estimated glomerular filtration rate; HbA Ic, hemoglobin Alc; MDRD, modification of diet in renal disease equation; mMDRD, MDRD modified for Chinese equation; T2DM, type 2 diabetes mellitus. 
was obtained using the mMDRD equation (91.61 \pm 23.04$)$. The CKD-EPI-Asia (68.35 \pm 17.29$),$ CKD-EPI (64.97 \pm 16.38$)$, and Ruijin (67.32 \pm 15.28$)$ equations provided very similar estimations of eGFR for the $\geq 80$-year-old group (Figure 1).

\section{Subject characteristics according to the presence of reduced eGFR}

Table 2 compares the differences in the demographics and clinical characteristics regarding decreases in renal function between the various GFR estimation equations. In the case of GFR values of $<60 \mathrm{~mL} / \mathrm{min} / 1.73 \mathrm{~m}^{2}$, one can observe decreases in renal function of $28.9 \%, 39.1 \%, 11.8 \%$, $8.4 \%, 14.3 \%, 11.5 \%$, and $12.7 \%$ when estimated using the $\mathrm{eGFR}_{\mathrm{CG}}, \mathrm{eGFR}_{\mathrm{BIS} 1}$, eGFR ${ }_{\mathrm{MDRD}}$, eGFR ${ }_{\mathrm{mMDRD}}$, eGFR ${ }_{\text {CKD-EPI}}$,

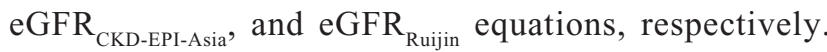
Although different methods for calculating eGFR were used in this study, patients with reduced renal function were older and mostly female (except for values calculated using the eGFR $_{\text {BIS1 }}$ equation), their conditions had been diagnosed for longer times, and the patients showed higher proportions of hypertension and albuminuria. There were significantly lower values of waist circumference and BMI for patients with reduced renal function compared with those with GFR $\geq 60$ $\mathrm{mL} / \mathrm{min} / 1.73 \mathrm{~m}^{2}$ according to the $\mathrm{CG}$ formula $(P<0.001)$.

\section{Status of albuminuria and decreased eGFR according to the different equations}

Albuminuria status and low eGFR $\left(<60 \mathrm{~mL} / \mathrm{min} / 1.73 \mathrm{~m}^{2}\right)$ as calculated by the different equations are shown in Table 3 .

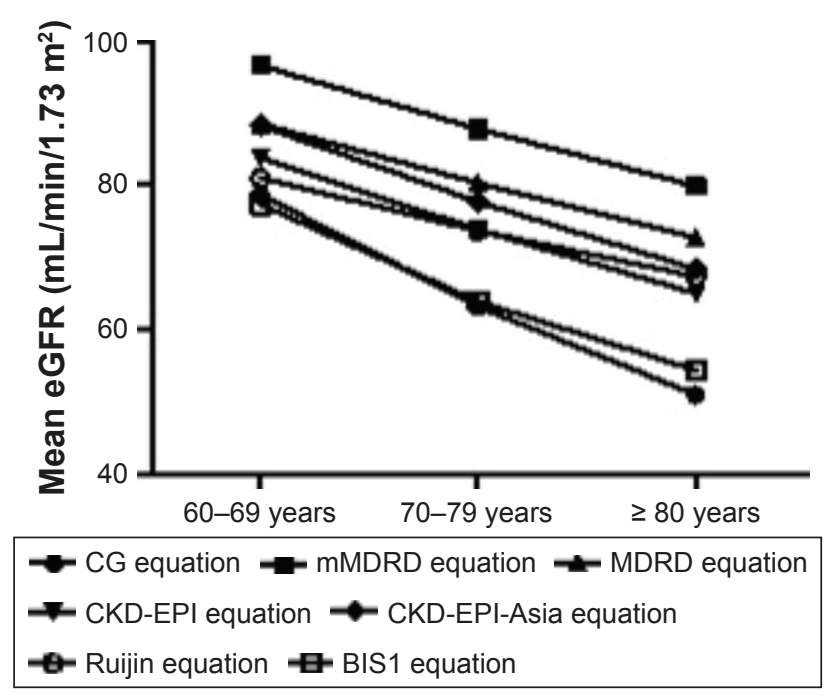

Figure I Estimated GFR of various equations by age groups.

Abbreviations: BISI, Berlin initiative study I equation; CG, Cockcroft-Gault; CKDEPI, chronic kidney disease epidemiology collaboration; eGFR, estimated glomerular filtration rate; MDRD, modification of diet in renal disease; mMDRD, MDRD modified for Chinese populations; Ruijin, Chinese Ruijin equation.
The total rate of albuminuria based on urine ACR $>30 \mathrm{mg} / \mathrm{g}$ was $35.2 \%$ (7,637), 31.0\% (6,717) with moderately increased (ACR 30-300 mg/g) and 4.2\% (920) with severely increased (ACR $>300 \mathrm{mg} / \mathrm{g}$ ) albuminuria. Most of the patients had albuminuria with eGFR $\geq 60 \mathrm{~mL} / \mathrm{min} / 1.73 \mathrm{~m}^{2}$ according to the various equations, ranging from $20.4 \%$ to $27.5 \%$. It can be seen that the calculated proportions of patients with both albuminuria and reduced renal function were quite similar among the MDRD (6.4\%), CKD-EPI (7.5\%), CKD-EPI-Asia $(6.3 \%)$, and Ruijin equations $(6.8 \%)$ but were higher for the BIS1 (16.2\%) and adjusted CG (12.9\%) equations and lower for the mMDRD equation $(4.8 \%)$. The concordance of albuminuria and decreased eGFR $\left(<60 \mathrm{~mL} / \mathrm{min} / 1.73 \mathrm{~m}^{2}\right)$ based on the different equations was poor according to both the Kappa $(<0.2)$ and ICC $(<0.4)$ statistics. The CKDEPI $(\mathrm{ICC}=0.243$, Kappa $=0.123)$ and Ruijin equations $(\mathrm{ICC}=0.240$, Kappa $=0.119)$ had a similar concordance.

\section{Comparison of the proportions of diabetic kidney disease stages calculated using the different equations}

Table 4 shows the calculated proportions of the various stages of CKD. The total proportion of CKD stages 1-5 was $51.2 \%, 58.7 \%, 40.6 \%, 38.7 \%, 42.0 \%, 40.4 \%$, and $41.1 \%$ according to the eGFR ${ }_{\mathrm{CG}}, \mathrm{eGFR}_{\mathrm{BIS} 1}, \mathrm{eGFR}_{\mathrm{MDRD}}, \mathrm{eGFR}_{\mathrm{mMDRD}}$, eGFR $_{\text {CKD-EPI}}$, eGFR CKD-EPI-Asia and eGFR Ruijin $_{\text {equations, }}$ respectively. Significant differences in the proportion of stage $1 \mathrm{CKD}$ were observed according to the various equations. The proportion of CKD stage $3 \mathrm{a}$ (eGFR $60-45 \mathrm{~mL} /$ $\min / 1.73 \mathrm{~m}^{2}$ ) was $20.6 \%$ as calculated by the CG equation, $29.6 \%$ as calculated by the BIS 1 equation, $5.7 \%$ as calculated by the mMDR equation, $8.5 \%$ as calculated by the MDRD equation, $10.1 \%$ as calculated by the CKD-EPI equation, $8.0 \%$ as calculated by the CKD-EPI-Asia equation, and $10.0 \%$ as calculated by the Ruijin equation. The proportion of CKD stage ( $3 \mathrm{~b}-5$, eGFR $<45 \mathrm{~mL} / \mathrm{min} / 1.73 \mathrm{~m}^{2}$ ) was $8.3 \%$, $9.5 \%, 2.7 \%, 3.3 \%, 4.2 \%, 3.5 \%$, and $2.7 \%$ as calculated by

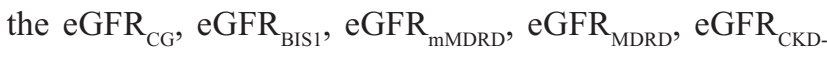

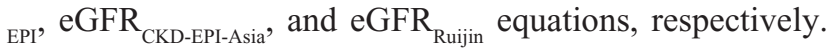
Similar proportions of stage $2(22.9 \%, 20.0 \%)$ and stage $3 \mathrm{a}$ $(10.1 \%, 10.0 \%)$ CKD were identified by the CKD-EPI and Ruijin equations (Table 4 ).

In general, Table 5 reveals good concordance among these creatinine-based equations in classifying CKD stages. High concordance was observed among the MDRD, CKD-EPI-Asia, CKD-EPI, and Ruijin equations. The lowest concordance was observed between the BIS1 and mMDRD equations. The CKD-EPI-Asia equation exhibited excellent concordance with the MDRD (ICC: 0.963), 
Table 2 Demographic and clinical characteristics of subjects by reduced renal function according to different GFR estimated equations

\begin{tabular}{|c|c|c|c|c|c|c|}
\hline \multirow[t]{5}{*}{ Variables } & \multicolumn{6}{|c|}{ Reduced renal function (eGFR $\left.<60 \mathrm{~mL} / \mathrm{min} / 1.73 \mathrm{~m}^{2}\right)$} \\
\hline & \multicolumn{2}{|c|}{ eGFR by adjusted CG } & \multicolumn{2}{|l|}{ eGFR by BISI } & \multicolumn{2}{|c|}{ eGFR by mMDRD } \\
\hline & No & Yes & No & Yes & No & Yes \\
\hline & $N=15,445$ & $\mathbf{N}=6,278$ & $N=13,228$ & $\mathbf{N}=8,495$ & $\mathbf{N}=19,907$ & $\mathbf{N}=\mathbf{I}, \mathbf{8} \mid \mathbf{6}$ \\
\hline & $(71.1)$ & $(28.9)$ & $(60.9)$ & $(39.1)$ & $(91.6)$ & (8.4) \\
\hline Age (years) & $68.35 \pm 6.09$ & $76.48 \pm 6.99 * * *$ & $67.96 \pm 6.08$ & $74.97 \pm 7.12 * * *$ & $70.28 \pm 7.17$ & $75.25 \pm 7.72 * * *$ \\
\hline Female & $7,616(49.3 \%)$ & $3,530(56.2 \%)^{* * *}$ & $7,850(59.3 \%)$ & $3,296(38.8 \%)^{* * *}$ & $10,126(50.9 \%)$ & $\mathrm{I}, 020(56.2 \%)^{* * *}$ \\
\hline Duration of T2DM (years) & $8.35 \pm 5.79$ & $10.42 \pm 7.06 * * *$ & $8.37 \pm 5.79$ & $9.85 \pm 6.81 * * *$ & $8.75 \pm 6.10$ & 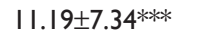 \\
\hline BMI $\left(\mathrm{kg} / \mathrm{m}^{2}\right)$ & $24.59 \pm 2.95$ & $23.25 \pm 2.85 * * *$ & $24.30 \pm 3.01$ & $24.04 \pm 2.93 * * *$ & $24.22 \pm 2.98$ & $24.03 \pm 3.00 *$ \\
\hline Waist circumference $(\mathrm{cm})$ & $85.34 \pm 7.75$ & $83.55 \pm 7.73 * * *$ & $84.53 \pm 7.66$ & $85.28 \pm 7.97 * * *$ & $84.82 \pm 7.76$ & $84.90 \pm 8.10$ \\
\hline Abdominal obese (yes) & 8,252 (72.7\%) & $3,101(27.3 \%)^{* * *}$ & 7,288 (55.1\%) & $4,065(47.9 \%)^{* * *}$ & 10,346 (91.1\%) & I,007 (8.9\%)** \\
\hline Fasting glucose (mmol/L) & $8.15 \pm 2.77$ & $8.02 \pm 2.86 * *$ & $8.15 \pm 2.82$ & $8.04 \pm 2.77 * *$ & $8.11 \pm 2.78$ & $8.13 \pm 2.96$ \\
\hline HbAlc (\%) & $7.3 \mathrm{I} \pm \mathrm{I} .70$ & $7.23 \pm 1.75 * *$ & $7.32 \pm 1.72$ & $7.24 \pm 1.71 * *$ & $7.28 \pm 1.72$ & $7.34 \pm 1.71$ \\
\hline $\mathrm{HbAlc} \leq 7.0$ & 8,208 (53.1\%) & $3,455(55.0 \%)^{*}$ & 7,075 (53.5\%) & $4,588(54.0 \%)$ & 10,722 (53.9\%) & $94 \mid(5 \mid .8 \%)$ \\
\hline Scr $(\mathrm{mmol} / \mathrm{L})$ & $69.42 \pm 11.13$ & $99.05 \pm 36.48 * * *$ & $66.33 \pm 8.53$ & $96.11 \pm 31.88 * * *$ & $73.03 \pm 13.28$ & $|32.20 \pm 5| .67^{* * *}$ \\
\hline Hypertension (yes) & $8,883(57.5 \%)$ & $4,229(67.4 \%)^{* * *}$ & 7,517 (56.8\%) & $5,595(65.9 \%)^{* * *}$ & II,8I7 (59.4\%) & I,295 (7I.3\%)*** \\
\hline Albuminuria (yes) & $4,840(31.3 \%)$ & $2,797(44.6 \%)^{* * * *}$ & $4,128(31.2 \%)$ & $3,509(41.3 \%)^{* * *}$ & $6,594(33.1 \%)$ & $\mathrm{I}, 043(57.4 \%)^{* * *}$ \\
\hline
\end{tabular}

Notes: Subjects with missing data were excluded. Data are means \pm SD or $\mathrm{n}(\%)$. *Statistically significant difference of reduced renal function compared to those with eGFR $\geq 60 \mathrm{~mL} / \mathrm{min} / \mathrm{I} .73 \mathrm{~m}^{2}(P<0.05)$. **Statistically significant difference of reduced renal function compared to those with eGFR $\geq 60 \mathrm{~mL} / \mathrm{min} / \mathrm{I} .73 \mathrm{~m}{ }^{2}(P<0.0 \mathrm{I})$. *** $\mathrm{Statistically}$ significant difference of reduced renal function compared to those with with eGFR $\geq 60 \mathrm{~mL} / \mathrm{min} / 1.73 \mathrm{~m}^{2}(P<0.00 \mathrm{I})$.

Abbreviations: BISI, Berlin initiative study I equation; BMI, body mass index; CG, Cockcroft-Gault equation; CKD-EPI, chronic kidney disease epidemiology collaboration; eGFR, estimated glomerular filtration rate; EPI-Asian, CKD-EPI equation in Asians; HbAIc, hemoglobin Alc; MDRD, modification of diet in renal disease equation; mMDRD, MDRD modified for Chinese equation; Scr, serum creatinine; Ruijin, Chinese Ruijin equation; T2DM, type 2 diabetes mellitus.

Ruijin (ICC: 0.956), CKD-EPI (ICC: 0.931), and mMDRD (ICC: 0.892 ) equations, and the Ruijin equation exhibited high concordance with the CKD-EPI equation (ICC: 0.950) (Table 5). In addition, the BIS1 equation exhibited good concordance with the modified CG equation (ICC: 0.809). These results are consistent with the results of the BlandAltman plot shown in Figure 2. Increasing scatter of the differences with increasing values of eGFR was observed among the equations, especially with eGFR values of $\geq 90 \mathrm{~mL} /$ $\min / 1.73 \mathrm{~m}^{2}$ (Figure 2).

\section{Discussion}

This study included nearly all commonly used GFR estimating equations used for CKD in China. For the first time, high concordances were observed between the CKD-EPI-Asia equation and the MDRD, Ruijin, CKD-EPI, and mMDRD equations for the categorization of CKD stages after considering albuminuria in a large community sample of older diabetic patients. Good concordance was also observed between the BIS1 and modified CG equations.

This study found that the great majority of older diabetic patients (over 20.0\% according to the various equations) had mild kidney damage (albuminuria with eGFR $\geq 60 \mathrm{~mL} /$ $\min / 1.73 \mathrm{~m}^{2}$ ); this proportion was higher than that found in the UK study of general T2DM patients $(\sim 12.6 \%)$ and in the US study of patients $\geq 65$ years of age $(\sim 14.7 \%)$ using the CKD-EPI equation. ${ }^{36,37}$ This result was consistent with our previous study, which found that ethnic Chinese people may be prone to albuminuric diabetic kidney disease. ${ }^{27}$ The Ruijin and CKD-EPI equations had similar predictive values $(\sim 10.0 \%)$ for the early stage of reduced renal function (CKD stage $3 \mathrm{a})$.

The low concordance among all equations regarding the eGFR value of $\geq 90 \mathrm{~mL} / \mathrm{min} / 1.73 \mathrm{~m}^{2}$ was observed by both the CKD stage classification shown in Table 4 and the mean differences shown in Figure 2 (the Bland-Altman plot). This result is consistent with the report by the ADA consensus conference, which stated that the existing estimation equations had low precision at higher values of GFR. ${ }^{29,38}$ The question of whether the early course of diabetic kidney disease is associated with hyperfiltration in older patients with T2DM still needs further study.

In this large population of 21,723 older diabetic patients, it was not surprising that eGFR declined with age according to all these creatinine-based estimation equations. The decline found using the $\mathrm{CG}$ formula was much greater with advanced age. The finding that the CG formula identified a lower level of eGFR and a higher rate of CKD than the other equations was also reported by other studies..$^{23,39,40}$ This discrepancy may due to structural differences between the equations. The $\mathrm{CG}$ equation was originally based on the urinary creatinine excretion of hospitalized Caucasian men aged 18-92 years and with normal renal function. ${ }^{41}$ The estimation of GFR by the $\mathrm{CG}$ formula is proportional to body weight or BMI, as 


\begin{tabular}{|c|c|c|c|c|c|c|c|}
\hline \multicolumn{2}{|c|}{ eGFR by MDRD } & \multicolumn{2}{|c|}{ eGFR by CKD-EPI } & \multicolumn{2}{|c|}{ eGFR by EPI-Asian } & \multicolumn{2}{|l|}{ eGFR by Ruijin } \\
\hline No & Yes & No & Yes & No & Yes & No & Yes \\
\hline $\begin{array}{l}N=19,165 \\
(88.2)\end{array}$ & $\begin{array}{l}N=2,558 \\
(I I .8)\end{array}$ & $\begin{array}{l}N=18,6 \mid 3 \\
(85.7)\end{array}$ & $\begin{array}{l}N=3,110 \\
(14.3)\end{array}$ & $\begin{array}{l}N=19,220 \\
(88.5)\end{array}$ & $\begin{array}{l}\mathrm{N}=2,503 \\
(I I .5)\end{array}$ & $\begin{array}{l}N=18,954 \\
(87.3)\end{array}$ & $\begin{array}{l}N=2,769 \\
(12.7)\end{array}$ \\
\hline $70.11 \pm 7.10$ & $75.09 \pm 7.68^{* * *}$ & $69.84 \pm 6.96$ & $75.85 \pm 7.5 I^{* * *}$ & $70.00 \pm 7.04$ & $76.10 \pm 7.46 * * *$ & $70.01 \pm 7.06$ & $75.43 \pm 7.54 * * *$ \\
\hline 9,484 (49.5\%) & $\mathrm{I}, 662(65.0 \%)^{* * *}$ & $9,218(49.5 \%)$ & $1,928(62.0 \%)^{* * *}$ & $9,573(49.8 \%)$ & $1,573(62.8 \%)^{* * *}$ & $9,536(50.3 \%)$ & $1,610(58.1 \%)^{* * *}$ \\
\hline $8.69 \pm 6.05$ & $10.91 \pm 7.32^{* * *}$ & $8.66 \pm 6.02$ & $10.68 \pm 7.26 * * *$ & $8.68 \pm 6.05$ & II.06 $\pm 7.33 * * *$ & $8.68 \pm 6.04$ & $10.80 \pm 7.29$ \\
\hline $24.21 \pm 2.97$ & $24.12 \pm 3.05^{*}$ & $24.22 \pm 2.97$ & $24.10 \pm 3.02 *$ & $24.22 \pm 2.97$ & $24.08 \pm 3.04 *$ & $24.22 \pm 2.97$ & $24.10 \pm 3.03$ \\
\hline $84.58 \pm 7.75$ & $84.66 \pm 8.12$ & $84.83 \pm 7.75$ & $84.76 \pm 8.00$ & $84.84 \pm 7.75$ & $84.74 \pm 8.08$ & $84.8 I \pm 7.74$ & $84.95 \pm 8.11$ \\
\hline 9,839 (86.7\%) & $1,514(13.3 \%)^{* * *}$ & 9,545 (84.1\%) & $1,808(15.9 \%)^{* * *}$ & 9,89। (87.1\%) & $1,462(12.9 \%)^{* * *}$ & 9,779 (86.1\%) & $1,574(13.9 \%)^{* * *}$ \\
\hline $8.12 \pm 2.78$ & $8.06 \pm 2.92$ & $8.12 \pm 2.79$ & $8.03 \pm 2.87$ & $8.12 \pm 2.79$ & $8.02 \pm 2.91$ & $8.12 \pm 2.79$ & $8.03 \pm 2.88$ \\
\hline $7.29 \pm 1.72$ & $7.29 \pm 1.68$ & $7.29 \pm 1.72$ & $7.29 \pm 1.68$ & $7.29 \pm 1.72$ & $7.29 \pm 1.67$ & $7.29 \pm 1.72$ & $7.29 \pm 1.68$ \\
\hline 10,307 (53.8\%) & I,356 (53.0\%) & $10,002(53.7 \%)$ & $\mathrm{I}, 66 \mathrm{I}(53.4 \%)$ & 10,337 (53.8\%) & I,326 (53.0\%) & 10,188 (53.8\%) & I,475 (53.3\%) \\
\hline $72.30 \pm 12.90$ & $120.52 \pm 47.42^{* * *}$ & $71.65 \pm 12.33$ & II $5.85 \pm 44.47 * * *$ & $72.35 \pm \mid 2.91$ & $121.23 \pm 47.69 * * *$ & $71.86 \pm|2.3|$ & $119.84 \pm 45.57^{* * *}$ \\
\hline I I,3। 3 (59.0\%) & I,799 $(70.3 \%)^{* * *}$ & 10,927 (58.7\%) & $2,185(70.3 \%)^{* * *}$ & I I,323 (58.9\%) & I,789 (7I.5\%)*** & II,I 56 (58.9\%) & I,956 (70.6\%)*** \\
\hline 6,256 (32.6\%) & $\mathrm{I}, 38 \mathrm{I}(54.0 \%)^{* * *}$ & $6.017(32.3 \%)$ & $\mathrm{I}, 620(52.1 \%)^{* * *}$ & 6,272 (32.6\%) & $\mathrm{I}, 365(54.5 \%)^{* * *}$ & $6,161 \quad(32.5 \%)$ & $\mathrm{I}, 476(53.3 \%)^{* * *}$ \\
\hline
\end{tabular}

was verified by our study and other studies. ${ }^{42,43}$ The high rate of reduced GFR was identified by the CG formula and the BIS1 equation, possibly due to a systematic bias in terms of an overdiagnosis of CKD due to the (on average) lower body weight and decreased muscle mass in older diabetic Chinese patients compared with Caucasians. The mMDRD and Ruijin equations were both adapted from the four-variable MDRD equation, and the gold standard was ${ }^{99 \mathrm{~m}} \mathrm{Tc}$-DTPA plasma clearance. ${ }^{7,25}$ The mMDRD equation predicted a higher level of GFR and a relatively low CKD rate compared to the other equations, possibly due to the different average reference GFR in the collected sample. In total, 454 patients were randomly selected from 684 patients and used for the training model, and the remaining 230 patients were used to test the performance of the modified MDRD Chinese equation. Only 37 (5.4\%) of diabetic nephropathy was diagnosed in the entire sample. The reference GFR in mMDRD was $55.1 \pm 35.1$ (median 49.9) $\mathrm{mL} / \mathrm{min} / 1.73 \mathrm{~m}^{2} .7$ For comparison, the Ruijin formula was based on 670 people randomly selected from $760 \mathrm{CKD}$ patients, and the remaining 90 cases were used to test the modified equations. The reference GFR used in the Chinese Ruijin formula was $(51.26 \pm 30.49) \mathrm{mL} / \mathrm{min} / 1.73 \mathrm{~m}^{2}$ for males and $(54.36 \pm 34.94) \mathrm{mL} / \mathrm{min} / 1.73 \mathrm{~m}^{2}$ for females. Furthermore, $67(8.8 \%)$ of diabetic patients were included in this study. ${ }^{25}$

The four-variable MDRD equation was originally developed based on data from a study entitled Modification of Diet in Renal Disease, which included 1,628 mostly white
CKD patients. Among these patients, 1,070 were randomly selected as the training sample, and the remaining 558 were used for validation. Only 99 patients $(6.1 \%)$ in the sample had diabetes. The gold standard used to develop the MDRD equation was ${ }^{125} \mathrm{I}$-iothalamate clearance. The mean GFR for the entire population was $39.8 \mathrm{~mL} / \mathrm{min} / 1.73 \mathrm{~m}^{2}{ }^{5}$ The CKD-EPI equation used the same four variables adopted by the MDRD equation and was based on a cohort study that included 8,254 participants with and without CKD. Among the participants, 5,504 subjects were randomly selected for development, and the remaining subjects were used for validation. Patients with diabetes comprised almost $30 \%$ of the cohort. The mean GFR was $68 \mathrm{~mL} / \mathrm{min} / 1.73 \mathrm{~m}^{2} .{ }^{8}$ The CKD-EPI-Asia equation is based on the CKD-EPI data source, and the mean GFR was $57 \mathrm{~mL} / \mathrm{min} / 1.73 \mathrm{~m}^{2}$ in Asians. The equations were validated in different racial-ethnic groups (White and other, Black, Asian, Native American, and Hispanic groups), including studies conducted in China $(\mathrm{N}=675)$ and Japan $(\mathrm{N}=248)$. The overall number of patients with diabetes was 2,406 (29\%). ${ }^{12}$ Therefore, there is no standardized protocol for measuring GFR, and the diversity of the mean level of GFR and diabetic status found using different equations will influence the accuracy of the equations in predicting CKD in Chinese diabetic populations. The different standard methods of estimating GFR may influence the concordance. The Jaffe kinetic method was used in this study for creatinine measurement, and this may differ from other 


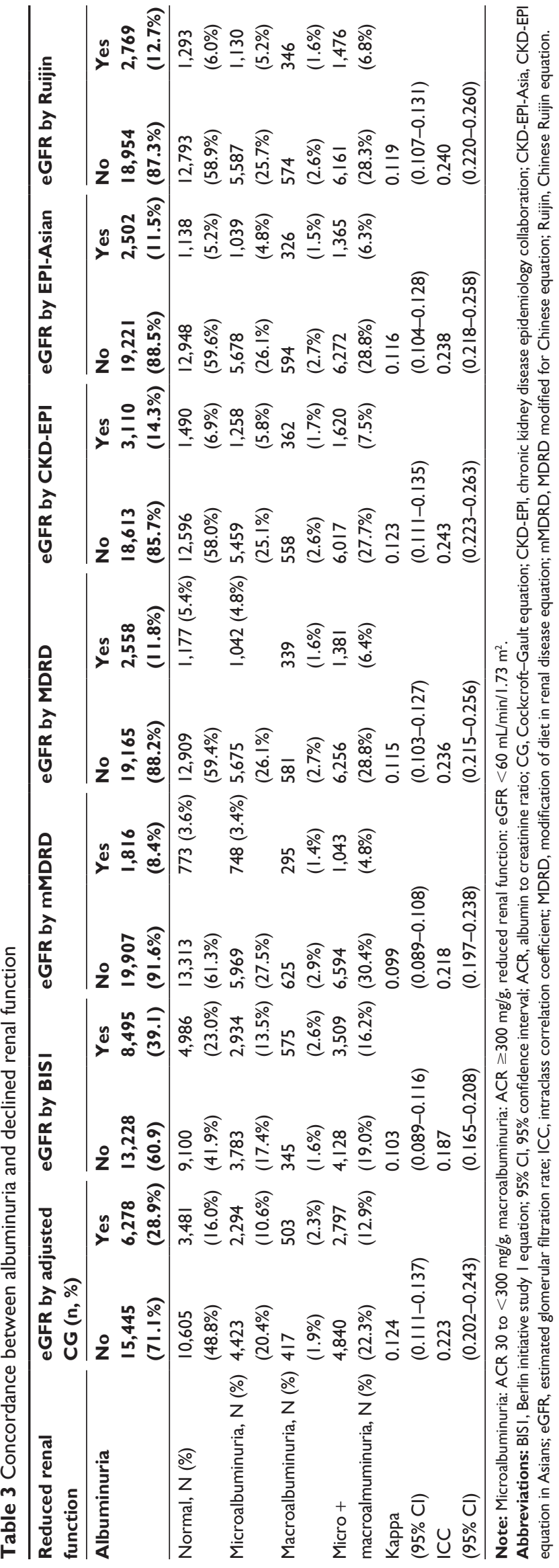

methods. Clinicians must understand that for populations such as the elderly, the use of the CG and other equations to estimate kidney function may yield different results. CG tends to overestimate reduced kidney function, which may result in over-diagnosis and unnecessary diseaselabeling, especially in elderly Chinese patients.

Approximately only $4.8 \%-12.9 \%$ of diabetic patients with both albuminuria and reduced renal function (eGFR $<60 \mathrm{~mL} / \mathrm{min} / 1.73 \mathrm{~m}^{2}$ ) were identified by the equations examined in this study. The low concordance between albuminuria and reduced renal function indicated the importance of adding albuminuria into CKD staging systems based on eGFR, especially for diabetic patients. Albuminuria has been considered a marker of impaired endothelial function and underlying damage to glomerular podocytes and an early clinical indicator of diabetic kidney disease. ${ }^{44,45}$ For older patients, debate continues regarding the influence of age on GFR. With aging, a wide variability of progressive decreases in GFR and renal blood flow was found among individuals. ${ }^{46}$ A 3-year prospective study on the CKD stage progression of people aged $\geq 65$ years revealed that older people with CKD exhibit a low progression of renal disease but are at higher risk for comorbidities related to $\mathrm{CKD}$ than for progression to ESRD. ${ }^{47}$ In addition, recent studies in both type 1 and 2 diabetes demonstrated that only some patients progress from microalbuminuria to macroalbuminuria and then further to ESRD. ${ }^{48-50}$ Bakris and Molitch suggested that only a subgroup of $25 \%-30 \%$ of diabetic patients with microalbuminuria will likely progress to more advanced stages of CKD. The presence of microalbuminuria alone is not predictive of CKD progression. ${ }^{51}$ Albuminuria may also be increased in some situations, including episodic hyperglycemia, high blood pressure, high protein diet, exercise, fever, urinary tract infection, and congestive heart failure. ${ }^{29}$ Thus, the measurement of kidney function is methodologically difficult due to the several different interlined functions of the kidney, which include the regulation of water and electrolyte levels, the excretion of waste products, acid-base homeostasis, and hormone secretion. ${ }^{52}$ The combined consideration and integrated management of malnutrition (undernutrition and overnutrition), hyperglycemia, hypoglycemia, hypertension, hyperuricemia, ${ }^{53}$ lipoprotein metabolism, systemic inflammation, anemia, and disordered mineral metabolism may alter the risks and benefit the progression of CKD and cardiovascular diseases in older diabetic patients.

In recent years, cystatin $\mathrm{C}$ has been proposed as a new endogenous marker of GFR, and several serum cystatin C-based equations have been developed and proposed for estimating the GFR as alternatives to Scr-based equations. Compared to 
Table 4 Proportions of stages of diabetic kidney disease according to the various estimating equations $(n=21,723)$

\begin{tabular}{|c|c|c|c|c|c|c|c|}
\hline eGFR in $\mathrm{mL} / \mathrm{min} / \mathrm{I} .73 \mathrm{~m}^{2}$ & CG & BISI & mMDRD & MDRD & CKD-EPI & CKD-EPI-Asia & Ruijin \\
\hline$\geq 60$ & $10,605(48.8)$ & $9,100(41.9)$ & $|3,3| 3(6 \mid .3)$ & $12,909(59.4)$ & $12,596(58.0)$ & 12,948 (59.6) & I2,793 (58.9) \\
\hline \multicolumn{8}{|c|}{ No kidney damage with normal or mildly } \\
\hline \multicolumn{8}{|l|}{ decreased eGFR } \\
\hline$\geq 90$ (stage I) & $84 I(3.9)$ & $149(0.7)$ & $3,430(15.8)$ & $2,380(I I .0)$ & $\mathrm{I}, 675(7.7)$ & $2,569(I I .8)$ & $\mathrm{I}, 197(5.5)$ \\
\hline \multicolumn{8}{|c|}{ Kidney damage with normal eGFR } \\
\hline 60-89 (stage 2) & $3,999(18.4)$ & $39,791(8.3)$ & $3,164(14.6)$ & $3,876(17.8)$ & $4,342(20.0)$ & $3,703(17.0)$ & $4,964(22.9)$ \\
\hline \multicolumn{8}{|c|}{ Kidney damage with mildly decreased eGFR } \\
\hline $45-60$ (stage 3a) & $4,478(20.6)$ & $6,427(29.6)$ & $\mathrm{I}, 228(5.7)$ & $\mathrm{I}, 847(8.5)$ & $2,194(10.1)$ & $\mathrm{I}, 748(8.0)$ & $2,173(10.0)$ \\
\hline \multicolumn{8}{|c|}{ Mild to moderately decreased eGFR } \\
\hline 30-45 (stage 3b) & I,49I (6.9) & $\mathrm{I}, 80 \mathrm{I}(8.3)$ & $432(2.0)$ & $550(2.5)$ & 701 (3.2) & $572(2.6)$ & $486(2.2)$ \\
\hline \multicolumn{8}{|c|}{ Moderate to severely decreased eGFR } \\
\hline 15-29 (stage 4) & $272(1.3)$ & $248(I . I)$ & $|2|(0.5)$ & $126(0.6)$ & I7I (0.8) & $142(0.7)$ & $100(0.5)$ \\
\hline \multicolumn{8}{|l|}{ Severely decreased eGFR } \\
\hline$<15$ (stage 5 ) & $37(0.2)$ & $19(0.1)$ & $35(0.2)$ & $35(0.2)$ & $44(0.2)$ & $4 \mid(0.2)$ & $10(0.0)$ \\
\hline \multicolumn{8}{|l|}{ Kidney failure } \\
\hline$<45$ (stage $3 b-5$ ) & $\mathrm{I}, 800(8.3)$ & $2,068(9.5)$ & $588(2.7)$ & $711(3.3)$ & $916(4.2)$ & $755(3.5)$ & $596(2.7)$ \\
\hline Total CKD stage I-5 & $\mathrm{II}, \mathrm{I} \mid \mathrm{I}(5 \mathrm{I} .2)$ & $12,623(58.1)$ & $8,410(38.7)$ & $8,814(40.6)$ & $9,127(42.0)$ & $8,775(40.4)$ & $8,930(4 I . I)$ \\
\hline
\end{tabular}

Note: Data presented as n (\%).

Abbreviations: BISI, Berlin initiative study I equation; CG, Cockcroft -Gault equation; CKD, chronic kidney disease; CKD-EPI, chronic kidney disease epidemiology collaboration; CKD-EPI-Asia, CKD-EPI equation in Asians; eGFR, estimated glomerular filtration rate; MDRD, modification of diet in renal disease equation; mMDRD, MDRD modified for Chinese equation; Ruijin, Chinese Ruijin equation.

creatinine-based measurement, cystatin $\mathrm{C}$ was considered to be less biased by age, gender, race and body weight. ${ }^{54}$ One proposed equation is the CKD-EPI creatinine and cystatin formula, which uses both Scr and serum cystatin levels for estimating kidney function. ${ }^{55,56}$ However, the high cost of the cystatin C assay and the lack of specificity for CKD have limited the use of cystatin $\mathrm{C}$ as the first-line measure of kidney function. ${ }^{57} \mathrm{To}$ avoid misclassification and mistreatment, some studies have suggested using cystatin $\mathrm{C}$ as a supplement to Scr for estimating the risk of adverse outcomes and the diagnosis of mildto-moderate decreases in GFR (eGFR: $45-59 \mathrm{~mL} / \mathrm{min} / 1.73$ $\left.\mathrm{m}^{2}\right){ }^{58,59}$ The use of albuminuria combined with cystatin $\mathrm{C}$ may benefit the risk stratification and management of early stage diabetic kidney disease (GFR values between 60 and $90 \mathrm{~mL} /$ $\mathrm{min} / 1.73 \mathrm{~m}^{2}$ ), where changes in Scr are not observed.

One of the strengths of the study was the large sample size from a community of elderly Chinese diabetic patients based on the EHR information system. This was the first time that the concordance of different creatinine-based GFR estimation equations was evaluated and analyzed in such a large sample of diabetic patients. Also, the selection bias may have been reduced by deleting the data for patients with highly abnormal Scr levels. The data were obtained from one southern district of Shanghai, and the results need to be verified in other districts or regions of China. In addition, prospective studies evaluating the ESRD, mortality, and cardiovascular disease outcomes based on different eGFR equations may provide more valid evidence for accurately identifying patients with early stage diabetic kidney diseases. The main limitation of the study was the unavailability of gold standard isotopic GFR measurements for comparison; therefore, the accuracy and precision of these formulae are not known. However, it has been suggested that the CKD-EPI equation predicts a reasonable distribution of eGFR values

Table 5 Intraclass-correlation coefficients for 5 stages of diabetic kidney disease according to different equations

\begin{tabular}{|c|c|c|c|c|c|c|}
\hline $\begin{array}{l}\text { eGFR }(\mathrm{mL} / \\
\left.\mathrm{min} / \mathrm{I} .73 \mathrm{~m}^{2}\right)\end{array}$ & CG & BISI & mMDRD & MDRD & CKD-EPI & CKD-EPI-Asia \\
\hline BISI & $0.809(0.804-0.8 \mid 4)$ & & & & & \\
\hline mMDRD & $0.552(0.540-0.564)$ & $0.462(0.447-0.476)$ & & & & \\
\hline MDRD & $0.662(0.653-0.67 I)$ & $0.562(0.550-0.574)$ & $0.897(0.894-0.900)$ & & & \\
\hline CKD-EPI & $0.736(0.729-0.743)$ & $0.635(0.626-0.645)$ & $0.823(0.819-0.828)$ & $0.932(0.930-0.934)$ & & \\
\hline CKD-EPI-Asia & $0.667(0.658-0.676)$ & $0.566(0.555-0.578)$ & $0.892(0.889-0.895)$ & $0.963(0.962-0.964)$ & $0.931(0.929-0.932)$ & \\
\hline Ruijin & $0.688(0.680-0.697)$ & $0.590(0.579-0.60 \mathrm{I})$ & $0.868(0.864-0.87 I)$ & $0.953(0.952-0.954)$ & $0.950(0.949-0.95 \mathrm{I})$ & $0.956(0.955-0.957)$ \\
\hline
\end{tabular}

Note: Data presented as intraclass-correlation coefficient ( $95 \%$ confidence interval).

Abbreviations: BISI, Berlin initiative study I equation; CG, Cockcroft-Gault equation; CKD-EPI, chronic kidney disease epidemiology collaboration; CKD-EPI-Asia, CKDEPI equation in Asians; eGFR, estimated glomerular filtration rate; MDRD, modification of diet in renal disease equation; mMDRD, MDRD modified for Chinese equation; Ruijin, Chinese Ruijin equation. 

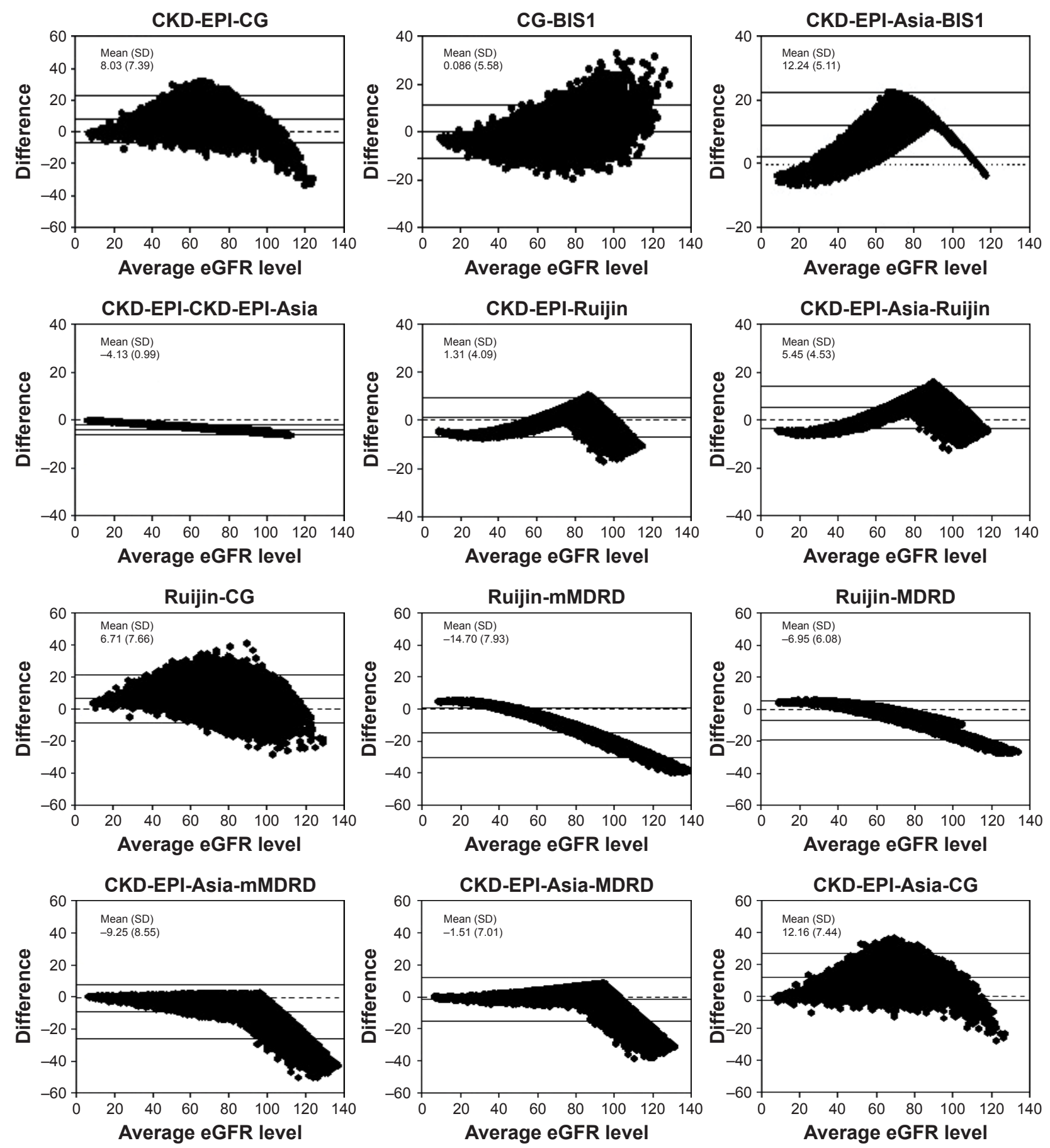

Figure 2 The Bland-Altman plots showing the comparisons between different eGFR equations

Notes: The average eGFR level between the two methods in $\mathrm{mL} / \mathrm{min} / 1.73 \mathrm{~m}^{2}$ ( $\mathrm{x}$-axis) is plotted against their difference ( $y$-axis). Mean and SD of the difference are reported to quantify the extent of the bias.

Abbreviations: BISI, Berlin initiative study I equation; CG, Cockcroft-Gault; CKD-EPI, chronic kidney disease epidemiology collaboration; eGFR, estimated glomerular filtration rate; MDRD, modification of diet in renal disease; mMDRD, MDRD modified for Chinese populations; Ruijin, Chinese Ruijin equation.

in healthy Chinese adult populations compared with the MDRD equation. ${ }^{12}$ Prospective studies are needed to verify these equations. Recently, a practical method of measuring GFR by iohexol clearance using dried capillary blood spots was developed and has been suggested to be a convenient method for accurately evaluating renal function. ${ }^{60,61}$ Improved methods and individualized considerations for measuring or estimating GFR will lead to a better ability to accurately identify early changes in GFR and to track GFR changes over time in patients with diabetes in clinical practice. 


\section{Conclusion}

The CKD-EPI-Asia equation resulted in excellent concordance with the CKD-EPI, MDRD, mMDRD, and Ruijin equations for the classification of CKD stages after considering albuminuria in a large community sample of older diabetic patients, whereas the BIS1 equation exhibited good concordance with the $\mathrm{CG}$ equation. In addition, significant differences were observed for stage $1 \mathrm{CKD}$ among the studied equations.

Low concordance between albuminuria and reduced renal function was observed for all creatinine-based equations. Accurate GFR estimates are difficult to obtain using creatinine-based equations in older diabetic patients. Kidney function is complex, and staff need to be aware of the individualized consideration and management of other risk factors or markers of reduced renal function in clinical practice.

\section{Acknowledgments}

The study was supported by postdoctoral program of Fudan university, grants from the Key Disease Project of Integrated Traditional and Western Medicine of Shanghai Municipality (zxbz2012-19, 2009MW02, 2009MHZ111), the Biobank of the Fifth People's Hospital of Shanghai, Fudan University, and by the Natural Science Foundation of Minhang District (2012MHZ016). The funding agencies were not involved in the study design, interpretation of the data, or writing the paper. The authors thank the members of Shanghai Minhang CDC who helped with the data collection process and with the quality control of the data.

\section{Disclosure}

The authors report no conflicts of interest in this work.

\section{References}

1. Liu ZH. Nephrology in china. Nat Rev Nephrol. 2013;9(9):523-528.

2. Cao Y, Li W, Yang G, Liu Y, Li X. Diabetes and hypertension have become leading causes of CKD in Chinese elderly patients: a comparison between 1990-1991 and 2009-2010. Int Urol Nephrol. 2012; 44(4):1269-1276.

3. Lin J, Knight EL, Hogan ML, Singh AK. A comparison of prediction equations for estimating glomerular filtration rate in adults without kidney disease. J Am Soc Nephrol. 2003;14(10):2573-2580.

4. Cockcroft DW, Gault M. Prediction of creatinine clearance from serum creatinine. Nephron. 1976;16(1):31-41.

5. Levey AS, Bosch JP, Lewis JB, Greene T, Rogers N, Roth D. A more accurate method to estimate glomerular filtration rate from serum creatinine: a new prediction equation. Modification of diet in renal disease study group. Ann Intern Med. 1999;130(6):461-470.

6. Levey A, Greene T, Kusek J. A simplified equation to predict glomerular filtration rate from serum creatinine. J Am Soc Nephrol. 2000; 155A:Abstract.

7. Ma YC, Zuo L, Chen JH, et al. Modified glomerular filtration rate estimating equation for Chinese patients with chronic kidney disease. $J \mathrm{Am}$ Soc Nephrol. 2006;17(10):2937-2944.
8. Levey AS, Stevens LA, Schmid CH, et al. A new equation to estimate glomerular filtration rate. Ann Intern Med. 2009;150(9):604-612.

9. Cruz-Jentoft AJ, Landi F, Schneider SM, et al. Prevalence of and interventions for sarcopenia in ageing adults: a systematic review. Report of the International Sarcopenia Initiative (EWGSOP and IWGS). Age Ageing. 2014;43(6):748-759.

10. Zaman T, Filipowicz R, Beddhu S. Implications and importance of skeletal muscle mass in estimating glomerular filtration rate at dialysis initiation. J Ren Nutr. 2013;23(3):233-236.

11. Deurenberg P, Deurenberg-Yap M, Guricci S. Asians are different from Caucasians and from each other in their body mass index/body fat per cent relationship. Obes Rev. 2002;3(3):141-146.

12. Stevens LA, Claybon MA, Schmid CH, et al. Evaluation of the chronic kidney disease epidemiology collaboration equation for estimating the glomerular filtration rate in multiple ethnicities. Kidney Int. 2011; 79(5):555-562.

13. American Diabetes Association. Standards of medical care in diabetes2015: summary of revisions. Diabetes Care. 2015;38(Suppl 1):S4.

14. Wang Y, Katzmarzyk PT, Horswell R, Zhao W, Johnson J, Hu G. Comparison of the heart failure risk stratification performance of the CKD-EPI equation and the MDRD equation for estimated glomerular filtration rate in patients with Type 2 diabetes. Diabet Med. 2016;33(5):609-620.

15. Targher G, Zoppini G, Mantovani W, et al. Comparison of two creatinine-based estimating equations in predicting all-cause and cardiovascular mortality in patients with type 2 diabetes. Diabetes Care. 2012; 35(11):2347-2353.

16. Matsushita K, Mahmoodi BK, Woodward M, et al. Comparison of risk prediction using the CKD-EPI equation and the MDRD study equation for estimated glomerular filtration rate. JAMA. 2012;307(18): 1941-1951.

17. Rossing P, Rossing K, Gaede P, Pedersen O, Parving HH. Monitoring kidney function in type 2 diabetic patients with incipient and overt diabetic nephropathy. Diabetes Care. 2006;29(5):1024-1030.

18. Lee EY, Lee YM, Choi KH, Lee HC, Lee BW, Kim BS. Comparison of two creatinine-based equations for predicting decline in renal function in type 2 diabetic patients with nephropathy in a Korean population. Int J Endocrinol. 2013;2013:848963.

19. Al-Maqbali SR, Mula-Abed WA. Comparison between three different equations for the estimation of glomerular filtration rate in omani patients with type 2 diabetes mellitus. Sultan Qaboos Univ Med J. 2014; 14(2):e197-e203.

20. Rognant N, Lemoine S, Laville M, Hadj-Aissa A, Dubourg L. Performance of the chronic kidney disease epidemiology collaboration equation to estimate glomerular filtration rate in diabetic patients. Diabetes Care. 2011;34(11):1320-1322.

21. Wang L, Tan M, Chang H. Clinical application of glomerular filtration rate estimation equation in elderly patients with diabetes mellitus. Acta Universitatis Medicinalis Anhui. 2012;1:89-93.

22. Chang H, Ye S. Application of modified glomerular filtration rate estimation equations in chinese diabetic patients with chronic kidney diseases. West Indian Med J. 2015;64(3):209.

23. Xie YY, Zhou LP, Yu YR. A comparison of different estimation equations for glomerular filtration rate in Chinese diabetic patients. Sichuan Da Xие Xие Baо Yi Xиe Ban. 2014;45(4):685-690.

24. Sun K, Jing C, Liu Y, et al. Application of estimated glomerular filtration rate formulae for different stages of chronic kidney disease in diabetes. Chin J Dis Control Prev. 2015;3:313-315.

25. Shi H, Chen N, Zhang W, et al. Evaluating and refitting the simplified equation of MDRD to predict glomerular filtration rate in Chinese patients with chronic kidney disease. Chin J Pract Int Med. 2006;26(9):665-669.

26. Schaeffner ES, Ebert N, Delanaye P, et al. Two novel equations to estimate kidney function in persons aged 70 years or older. Ann Intern Med. 2012;157(7):471-481.

27. Guo M, Niu JY, Li SR, et al. Gender differences in the association between hyperuricemia and diabetic kidney disease in community elderly patients. J Diabetes Complications. 2015;29(8):1042-1049. 
28. Rossing P, Rossing K, Gaede P, Pedersen O, Parving HH. Monitoring kidney function in type 2 diabetic patients with incipient and overt diabetic nephropathy. Diabetes Care. 2006;29(5):1024-1030.

29. Tuttle KR, Bakris GL, Bilous RW, et al. Diabetic kidney disease: a report from an ADA consensus conference. Diabetes Care. 2014;37(10): 2864-2883.

30. Stevens PE, Levin A. Evaluation and management of chronic kidney disease: synopsis of the kidney disease: improving global outcomes 2012 clinical practice guideline. Ann Intern Med. 2013;158(11):825-830.

31. Chen C, Lu FC. The guidelines for prevention and control of overweight and obesity in Chinese adults. Biomed Environ Sci. 2004; 17(Suppl): 1-36.

32. Grundy SM, Cleeman JI, Daniels SR, et al. Diagnosis and management of the metabolic syndrome: an American Heart Association/National Heart, Lung, and Blood Institute Scientific Statement. Circulation. 2005; 112(17):2735-2752.

33. Landis JR, Koch GG. The measurement of observer agreement for categorical data. Biometrics. 1977;33(1):159-174.

34. Hallgren KA. Computing inter-rater reliability for observational data: an overview and tutorial. Tutor Quant Methods Psychol. 2012; $8(1): 23-34$.

35. Bland JM, Altman DG. Statistical methods for assessing agreement between two methods of clinical measurement. Lancet. 1986;1(8476): 307-310.

36. Hill CJ, Cardwell CR, Patterson CC, et al. Chronic kidney disease and diabetes in the national health service: a cross-sectional survey of the U.K. National diabetes audit. Diabet Med. 2014;3(4):448-454.

37. Bailey RA, Wang Y, Zhu V, Rupnow MF. Chronic kidney disease in US adults with type 2 diabetes: an updated national estimate of prevalence based on kidney disease: improving global outcomes (KDIGO) staging. BMC Res Notes. 2014;7:415.

38. Magee GM, Bilous RW, Cardwell CR, Hunter SJ, Kee F, Fogarty DG. Is hyperfiltration associated with the future risk of developing diabetic nephropathy? A meta-analysis. Diabetologia. 2009;52(4):691-697.

39. Michels WM, Grootendorst DC, Verduijn M, Elliott EG, Dekker FW, Krediet RT. Performance of the Cockcroft-Gault, MDRD, and new CKD-EPI formulas in relation to GFR, age, and body size. Clin J Am Soc Nephrol. 2010;5(6):1003-1009.

40. Kurtal H, Schwenger V, Azzaro M, et al. Clinical value of automatic reporting of estimated glomerular filtration rate in geriatrics. Gerontology. 2009;55(3):288-295.

41. Gault MH, Longerich LL, Harnett JD, Wesolowski C. Predicting glomerular function from adjusted serum creatinine. Nephron. 1992; 62:249-256.

42. Rigalleau V, Lasseur C, Perlemoine C, et al. Cockcroft-Gault formula is biased by body weight in diabetic patients with renal impairment. Metabolism. 2006;55(1):108-112.

43. Rigalleau V, Lasseur C, Perlemoine C, et al. Estimation of glomerular filtration rate in diabetic subjects: cockcroft formula or modification of diet in renal disease study equation?. Diabetes Care. 2005;28(4): 838-843.

44. Siddiqi FS, Advani A. Endothelial-podocyte crosstalk: the missing link between endothelial dysfunction and albuminuria in diabetes. Diabetes. 2013;62(11):3647-3655.
45. Bakris GL, Molitch M. Microalbuminuria as a risk predictor in diabetes: the continuing saga. Diabetes Care. 2014;37(3):867-875.

46. Weinstein JR, Anderson S. The aging kidney: physiological changes. Adv Chronic Kidney Dis. 2010;17(4):302-307.

47. Giannelli SV, GrafCE, Herrmann FR, et al. Natural history of older adults with impaired kidney function: the InCHIANTI study. Rejuvenation Res. 2011;14(5):513-523.

48. de Boer IH, Rue TC, Cleary PA, et al. Long-term renal outcomes of patients with type 1 diabetes mellitus and microalbuminuria: an analysis of the diabetes control and complications trial/epidemiology of diabetes interventions and complications cohort. Arch Intern Med. 2011;171(5): 412-420.

49. Molitch ME, Steffes M, Sun W, et al. Development and progression of renal insufficiency with and without albuminuria in adults with type 1 diabetes in the diabetes control and complications trial and the epidemiology of diabetes interventions and complications study. Diabetes Care. 2010;33(7):1536-1543.

50. Adler AI, Stevens RJ, Manley SE, Bilous RW, Cull CA, Holman RR. Development and progression of nephropathy in type 2 diabetes: the United Kingdom Prospective Diabetes Study (UKPDS 64). Kidney Int. 2003;63(1):225-232.

51. Fox CS, Gona P, Larson MG, et al. A multi-marker approach to predict incident CKD and microalbuminuria. J Am Soc Nephrol. 2010; 21(12):2143-2149.

52. Sandilands EA, Dhaun N, Dear JW, Webb DJ. Measurement of renal function in patients with chronic kidney disease. Br J Clin Pharmacol. 2013;76(4):504-515.

53. Lytvyn Y, Perkins BA, Cherney DZ. Uric acid as a biomarker and a therapeutic target in diabetes. Can J Diabetes. 2015;39(3):239-246.

54. Filler G, Bokenkamp A, Hofmann W, Le Bricon T, Martinez-Bru C, Grubb A. Cystatin C as a marker of GFR - history, indications, and future research. Clin Biochem. 2005;38(1):1-8.

55. Inker $\mathrm{LA}, \mathrm{Schmid} \mathrm{CH}$, et al. Estimating glomerular filtration rate from serum creatinine and cystatin C. N Engl J Med. 2012;367(1):20-29.

56. Ye X, Liu X, Song D, et al. Estimating glomerular filtration rate (GFR) by serum creatinine or/and cystatin C equations: an analysis of multicenter Chinese subjects. Nephrology (Carlton). 2016;21(5):372-378.

57. Rule AD, Bailey KR, Lieske JC, Peyser PA, Turner ST. Estimating the glomerular filtration rate from serum creatinine is better than from cystatin $\mathrm{C}$ for evaluating risk factors associated with chronic kidney disease. Kidney Int. 2013;83(6):1169-1176.

58. Ferguson TW, Komenda P, Tangri N. Cystatin C as a biomarker for estimating glomerular filtration rate. Curr Opin Nephrol Hypertens. 2015; 24(3):295-300.

59. Rule AD, Glassock RJ. GFR estimating equations: getting closer to the truth? Clin J Am Soc Nephrol. 2013;8(8):1414-1420.

60. Mafham MM, Niculescu-Duvaz I, Barron J, et al. A practical method of measuring glomerular filtration rate by iohexol clearance using dried capillary blood spots. Nephron Clin Pract. 2007;106(3):c104-c112.

61. Maahs DM, Bushman L, Kerr B, et al. A practical method to measure GFR in people with type 1 diabetes. J Diabetes Complications. 2014; 28(5):667-673.
Clinical Interventions in Aging

\section{Publish your work in this journal}

Clinical Interventions in Aging is an international, peer-reviewed journal focusing on evidence-based reports on the value or lack thereof of treatments intended to prevent or delay the onset of maladaptive correlates of aging in human beings. This journal is indexed on PubMed Central, MedLine,

\section{Dovepress}

CAS, Scopus and the Elsevier Bibliographic databases. The manuscript management system is completely online and includes a very quick and fair peer-review system, which is all easy to use. Visit http://www.dovepress. com/testimonials.php to read real quotes from published authors. 